Filol. linguíst. port., São Paulo, 15(1), p. 305-333, Jan./Jun. 2013.

DOI: 10.11606/issn.2176-9419.v15i1p305-333.

\title{
Concepção(ões) de texto em contexto de EaD semipresencial
}

Text conception(s) in context of semi-present Distance Learning $(D L)$

\author{
Fabiana Komesu ${ }^{1}$ \\ Universidade Estadual Paulista (UNESP), \\ Brasil. \\ komesu@ibilce.unesp.br
}

\begin{abstract}
Resumo: A exemplo do que propõe Corrêa (2011) na investigação de textos produzidos por universitários e pré-universitários em duas diferentes situações de avaliação, procuro, neste trabalho, aproximar aspectos "ocultos" no ensino de escrita na universidade (Street, 2009) de reflexões produzidas no âmbito dos estudos da linguagem, em particular, aquelas propostas por Voloshinov/Bakhtin (s/d: 1926) no que se refere à noção de "presumido social". Interessa-me, de maneira particular, investigar concepção(ões) de texto em contexto digital, por meio do estudo de recursos semióticos atualizados na produção do universitário que utiliza computador com acesso à internet no processo de Educação a Distância (EaD) semipresencial. O conjunto do material é formado de 29 (vinte e nove) textos produzidos por alunos do Curso Pedagogia semipresencial
\end{abstract}

${ }^{1}$ Este trabalho foi redigido durante estágio de pós-doutoramento financiado pelo CNPq - Conselho Nacional de Desenvolvimento Científico e Tecnológico - Brasil, no período de janeiro a julho de 2012 (processo 163174/2011-3), na Universidade de São Paulo, sob supervisão do professor doutor Manoel Luiz Gonçalves Corrêa, cuja contribuição está presente em vários momentos deste texto e a quem agradeço pela oportunidade de interlocução constante. Agradeço também a professora doutora Renira Rampazzo Gambarato, da Tallinn University Baltic Film and Media School, Estônia, pela oportunidade de interlocução e pelos esclarecimentos na área de design e programação visual. 
da Univesp (Universidade Virtual do Estado de São Paulo), disciplina "Educação e Linguagem", no ano de 2010. A análise, de cunho qualitativo, procura mostrar que, do ponto de vista da instituição, há prevalência de aspectos estruturais e procedimentais nas instruções para realização da proposta da atividade; do ponto de vista do universitário, observa-se que a produção é caracterizada por concepção tradicional de texto, reconhecida, principalmente, por texto verbal escrito, embora a proposta priorizasse relação entre linguagem verbal e não verbal. Do ponto de vista dos estudos linguístico-discursivos, proponho refletir sobre uma concepção de texto que privilegie a integração entre múltiplas semioses, considerando-se o caráter de interlocução sócio-histórica estabelecido com enunciados alheios.

Palavras-chave: escrita; universitário; educação a distância.

Abstract: By following the example proposed by Corrêa (2011) in the investigation of texts produced by undergraduate and pre-undergraduate students in two different assessment, this work aims to approach "hidden" aspects in the teaching of writing at the university (Street, 2009), to reflections produced in the language field, in particular the ones referred as "socially assumed", proposed by Voloshinov/Bakhtin (s/d: 1926). It is particularly important to investigate the conception of text in digital context, by means of the study of updated semiotic resources in the production of undergraduate students using a computer with internet access in the process of semi-present Distance Learning (DL). The collected material comprises 29 (twenty nine) texts which were produced by students of the semipresent Pedagogy Course from Univesp (Universidade Virtual do Estado de São Paulo - Virtual University from the state of São Paulo), who were studying "Education and Language", in 2010. This qualitative analysis aims to show that regarding the institution there is a prevalence of structural and procedural aspects for the accomplishment of the proposed activity and, regarding the undergraduate student it is noticed that the production is characterized by a traditional conception of text, mainly recognized by written verbal text, although the proposal prioritized the relation between verbal and non verbal language. Regarding discursive-linguistic studies, it is important to reflect about a text conception that privileges the integration of multiple semiosis by taking into account the socio-historical interlocution character established within utterances of others.

Keywords: writing; undergraduate; distance learning. 


\section{EaD e estudos da linguagem}

Quais seriam os pontos positivos da educação a distância, considerando-se a diversidade de contextos situados num país como o Brasil? O presidente da Associação Brasileira de Educação a Distância (Abed), Fredric Litto (2012), busca responder essa questão no portal da instituição (disponível em: www2.abed.org.br. Acesso em 17 abr. 2012), já que se trata de uma das perguntas mais frequentes sobre EaD. De uma perspectiva institucional, Litto avalia de forma francamente positiva a expansão do processo no País, levando-se em conta não apenas a possibilidade de acesso à educação formal e/ou informal, por parte de pessoas que trabalham para sustento pessoal ou da família e não podem frequentar aulas presenciais em horários tradicionais, mas também a possibilidade de acesso a formas de educação formal e/ou informal por parte de pessoas incapacitadas por deficiências físicas e mentais; por parte de pessoas que moram em lugares isolados ou afastados de centros convencionais de produção de conhecimento; por parte de pessoas que, por força maior (por exemplo, cuidados com crianças, pessoas enfermas ou de idade avançada), não podem se deslocar até centros convencionais de produção de conhecimento; por parte de pessoas que trabalham para manutenção e sustento e não podem frequentar aulas presenciais em horários tradicionais. Assim, "em vez de essas pessoas 'irem' até a escola, a escola vai até elas", o que permite, do ponto de vista das instituições envolvidas no processo, que mais cidadãos brasileiros participem de maneira assíncrona "de todas as atividades com todos os outros inscritos no curso, nos dias e horários mais convenientes" (Litto, 2012). Litto ressalta, enfim, a legitimidade da modalidade a distância, dada a oferta, cada vez mais frequente, de cursos de graduação e de pós-graduação por instituições de "grande reputação acadêmica" (Litto, 2012), a exemplo de universidades públicas.

Com efeito, em termos de políticas de ensino, procurei destacar, em trabalho anterior (Komesu, 2012), como as vantagens da criação de cursos na modalidade a distância têm sido amplamente divulgadas pelas instâncias federal e estadual, além das particulares. Não se trata, no caso de políticas públicas, de privilégio de governos atuais; a necessidade de descentralização, com formação de profissionais aptos a atuar nos municípios do País, com menos ônus para a Nação e os Estados, não é novidade. ${ }^{2}$ É com a proposta de ampliar e enfatizar o papel do Estado no cenário das políticas públicas de

\footnotetext{
${ }^{2}$ Moore e Kearsley (2007), por exemplo, propõem pensar cinco gerações de educação a distância: a primeira teria início com cursos de instrução por correspondência, ainda no final do século XIX na Europa, passando por transmissão por rádio
} 
Educação Superior que o Governo do Estado de São Paulo criou, em 2008, a Univesp - Universidade Virtual do Estado de São Paulo -, programa que congrega universidades e centros públicos, agências de fomento à pesquisa e fundações estaduais (Vogt et alii, 2009: 9-10). Em março de 2010, a Univesp deu início ao primeiro Curso de Pedagogia semipresencial, ${ }^{3}$ sob coordenação da Universidade Estadual Paulista "Júlio de Mesquita Filho" (Unesp). Em 19 de junho de 2012, o plenário da Assembleia Legislativa do Estado de São Paulo (Alesp) aprovou o Projeto de Lei 264/2012, que instituiu a criação da Fundação Universidade Virtual do Estado de São Paulo - Univesp. A Fundação Univesp passou a ser, assim, a quarta universidade paulista, ao lado da Unesp, Unicamp e USP, com autonomia didático-científica, administrativa e de gestão financeira e patrimonial. A Fundação está vinculada à Secretaria de Desenvolvimento, Ciência e Tecnologia e deverá iniciar as atividades em 2013. A meta é atingir, em quatro anos, 24 mil alunos, por meio da oferta de cursos de licenciatura em Língua Portuguesa e Matemática, bacharelado em Sistemas para Comércio Eletrônico e em Segurança da Informação, Tecnologia em Processos Gerenciais, licenciatura em Ciências, Engenharia da Computação e Engenharia de Produção, dentre outros.

O coordenador da Univesp, Carlos Vogt, destacou, por ocasião da assinatura do projeto de lei pelo Governador do Estado de São Paulo, Geraldo Alckmin, que a ideia da criação da Fundação Univesp "está associada com o bem-estar social e a promoção de cidadania" e argumentou que o ensino superior público paulista cobre, na atualidade, apenas $10 \%$ dos formandos do ensino médio e que a Fundação ampliará "o acesso do jovem à universidade" (Univesp, 2012). Se, do ponto de vista de instituições públicas e particulares de ensino, parece haver benefícios inquestionáveis decorrentes do processo de instauração da modalidade a distância no País, do ponto de vista dos estudos da linguagem, ainda não há concordância sobre efeitos resultantes do processo

e televisão, por universidades abertas, por teleconferência, até chegar à era da internet/web (MOORE e KEARSLEY, 2007, p.25-26). Freitas (2005), ao traçar panorama geral da história da EaD, lembra que, no Brasil, o Instituto Universal Brasileiro pode ser considerado a instituição mais antiga na promoção de educação a distância. Desde 1940, o IUB mantém cursos por correspondência para os que ambicionam "preparo ou complementação cultural ou profissional", mas não têm possibilidade de frequentar escola regular ou curso profissionalizante (disponível em: < http://www.institutouniversal.com.br/>. Acesso em: 09 ago. 2011) (ver Komesu, 2012).

${ }^{3}$ Apresento, na nota de rodapé $\mathrm{n}^{\circ}$. 6, definição das modalidades "a distância" e "semipresencial". 
de textualização quando da modificação do espaço da escrita - do papel para a tela do computador, com/sem acesso à internet - e do emprego de novos mecanismos de produção, reprodução e difusão de textos no contexto eletrônico, ainda que estudos procurem caracterizar a chamada "textualidade digital" em contextos diversos, como mostra Buzato (2007b), na menção a produção de material didático (Braga, 2004 apud Buzato, 2007b: 159), comunicação jornalística (Palácios; Mielniczuk, 2002 apud Buzato, 2007b: 159) e formação de leitores críticos (Lemke, 1998 apud Buzato, 2007b: 159).

No que se refere à investigação de práticas de leitura e escrita na contemporaneidade, também se destacam trabalhos que buscam descrever e analisar ambientes de ensino-aprendizagem em níveis diversos, mediados por recursos tecnológicos e comunicacionais (Landow, 2002; Pahl; Rowsell, 2005; Xavier, 2005; Braga, 2007; Buzato, 2007a; Araújo e Dieb, 2009; Gee; Hayes, 2011); ensino de línguas (Collins e Ferreira, 2004; Telles, 2009); formação de professores (Buzato, 2006; McKenna; Proctor, 2006; Araújo, 2007; Costa e Tavares, 2008; Collins, 2008; Freire, 2009). No que se refere à investigação do processo de textualização em contexto de Educação a Distância, observase, de uma perspectiva dos estudos da Educação e da Psicologia, ênfase no "aprimoramento da relação ensino-aprendizagem" (Sarmet; Abrahão, 2007) e na "eficácia" no processo de comunicação/formação (Maia et al., 2006), considerando-se a formação do chamado "aluno autônomo" (ver crítica de Belloni, 2009). Parece, no entanto, haver poucos trabalhos que buscam, de uma perspectiva linguístico-discursiva, problematizar o processo de textualização em contexto a distância.

A emergência de textos no âmbito da $\mathrm{EaD}$ não depende apenas das competências individuais do "aluno autônomo" e da formação do "professor coletivo", ou de infraestrutura tecnológica avançada; o processo de textualização insere-se na complexidade de relações sociais concretas que implicam interpelações e coerções não ditas - portanto, da ordem da não transparência dos sentidos - que não são, necessariamente, percebidas como tais pelos sujeitos da linguagem. Tenciono, pois, discutir neste artigo concepção(ões) de texto que emerge $(\mathrm{m})$ da multiplicidade de perspectivas em ambiente digital, de maneira particularizada, no ambiente de educação a distância semipresencial. A hipótese de partida é que a produção textual dos universitários é caracterizada por concepção tradicional de texto, reconhecida, principalmente, por base gráfica, embora as propostas de atividade do curso superior priorizem relação entre diferentes modos e recursos. O conjunto do material é formado de 29 (vinte e nove) textos produzidos por universitários do Curso Pedagogia semipresencial da Univesp, disciplina "Educação e Linguagem", no ano de 2010. $\mathrm{Na}$ análise, de cunho qualitativo, são consideradas as noções de letramento acadêmico (Lea; Street, 2006), de aspectos ocultos do letramento (Street, 
2009) e de presumido social (Voloshinov/Bakhtin, s/d: 1926) como modos de associar, a exemplo do que propõe Corrêa (2011) na avaliação de textos de pré-universitários e universitários, a perspectiva etnográfica à perspectiva linguístico-discursiva.

O artigo está organizado da seguinte maneira: problematizo, num primeiro momento, a noção de texto, procurando observar uma sua vinculação a gêneros do discurso. Discuto aspectos vinculados às práticas letradas acadêmicas do universitário em ambiente semipresencial para, em seguida, refletir sobre os dados. Apresento, por fim, considerações sobre o trabalho realizado e as referências bibliográficas.

\section{Texto como enunciado genérico}

No âmbito dos estudos das teorias de Texto e da Linguística Textual, ${ }^{4}$ é célebre a definição de texto proposta por Beaugrande e Dressler (1981: 1-13), segundo a qual texto é ocorrência comunicativa que reúne 7 (sete) aspectos de textualidade, princípios constitutivos e definidores da comunicação textual. São eles: (i) coesão, que diz respeito à forma como os componentes da chamada "superfície do texto" se encontram vinculados numa sequência; (ii) coerência, que se refere à articulação entre conceitos "que subjazem à superfície do texto", resultante de processos cognitivos dos "usuários" da língua; (iii) intencionalidade, concernente ao esforço do produtor em estabelecer comunicação eficiente capaz de satisfazer aos objetivos dos interlocutores envolvidos, visando aos objetivos específicos num plano de comunicação; (iv) aceitabilidade, que implica que o texto produzido também deve estar em consonância com a expectativa do receptor e que este deve se esforçar (cooperar) em compreender os textos produzidos; (v) informatividade, que diz respeito à medida em que as ocorrências do texto são esperadas (ou não), de conhecimento (ou não) do receptor - para os autores, quanto maior a informatividade, menor o interesse; quanto menor a informatividade, maior o interesse -; (vi) situacionalidade, adequação do texto a uma situação que mostra a relevância do que é dito e orienta a produção de sentidos, tanto da perspectiva do produtor quanto da do receptor; (vii) intertextualidade, aspecto segundo o qual a utilização de um texto depende do conhecimento de um ou mais textos prévios. Ainda que os autores procurem demonstrar a inter-relação entre esses

\footnotetext{
${ }^{4}$ Para uma análise sistematizada dos estudos de texto na área de Linguística Textual, ver Bentes (2008: 245-285).
} 
aspectos, afirmam que se qualquer uma dessas normas for não atendida, o texto não será comunicativo, será "não texto" (Beaugrande; Dressler, 1981).

Koch (2009: 29-33; 43-47), dentre outros autores (ver, por exemplo, Marcuschi, 1983; Bentes, 2008) reconhece a inegável contribuição de Beaugrande e Dressler (1981) na orientação cognitivista assumida pelos teóricos da Linguística Textual. No entanto, a autora apresenta objeções a essa teoria, como a inoperância, de um ponto de vista pragmático-cognitivo, da divisão entre propriedades centradas no texto e propriedades centradas nos sujeitos e na situação de comunicação, como se essa distinção pudesse ser efetivamente realizada; aponta também para o estatuto da coerência, que deveria ser entendida como resultante de múltiplos fatores, de uma construção dos sujeitos em determinada situação de comunicação; considera ainda a necessidade de observar aspectos como conhecimento partilhado, fatores de contextualização, mecanismos de relevância, fenômenos de focalização na investigação do funcionamento dos textos.

Costa Val (2004: 3-5), na análise de textos de vestibulandos, propõe uma releitura dos critérios apresentados por Beaugrande e Dressler (1981), reunindo-os sob aspectos pragmático (atuação informacional e comunicativa), semântico-conceitual (coerência) e formal (coesão). Destaco, em Costa Val (2004: 15), a crítica ao aspecto da intertextualidade, entendido, em Beaugrande e Dressler (1981), como aquele referente a fatores que tornam a utilização de um texto dependente do conhecimento de um ou mais textos prévios. Para Costa Val, se esse conhecimento factual prévio, ressaltado pelos autores, é necessário tanto para a fala coloquial quanto para pronunciamentos políticos ou midiáticos, é também verdade, segundo a autora, que Beaugrande e Dressler deixam de considerar "o discurso anônimo, o senso comum, a voz geral corrente que se faz ouvir na intertextualidade" (Costa Val, 2004: 15), tão fundamental na produtividade de atividades da/na linguagem quanto textos efetivamente conhecidos. Da perspectiva que assumo, a observação de Costa Val (2004) parece apontar para um caráter de interlocução sócio-histórica com outros textos, diálogo que pode ser reconhecido como traço constitutivo das atividades verbais humanas. Permite também refletir sobre concepção outra de sujeito, distinta de um quadro das ciências cognitivas, fundada, de certa forma, num quadro não subjetivista da linguagem.

Para o que me interessa, o que é discutido com base numa noção de texto equivalente à reunião de aspectos de textualidade pode ser pensado, diferentemente, com base numa noção de texto como enunciado genérico na proposta de Bakhtin e de seu Círculo (1997a; 1997b; s/d: 1926). É sabido que, para Bakhtin (1997a, 1997b), sejam quais forem os modos de utilização da língua, o locutor sempre a utiliza por meio de enunciados que refletem 
condições específicas da comunicação humana, as quais colocam em evidência uma sua filiação a certo gênero do discurso. Fundamentada nos pressupostos de Bakhtin, Machado (2005: 152; 157) argumenta que o gênero do discurso não é forma linguística, mas forma enunciativa apreendida em processos de interação, muito mais dependente do contexto comunicativo e da cultura do que da palavra em si. Dito de outro modo, na reflexão de Fiorin (2006), "Só se age na interação, só se diz no agir e o agir motiva certos tipos de enunciados, o que quer dizer que cada esfera de utilização da língua elabora tipos relativamente estáveis de enunciados." (Fiorin, 2006: 61). Assim, contrariamente à ideia de texto que privilegia mecanismos linguísticos resultantes de processos cognitivos, a concepção de texto/enunciado define em Bakhtin elo "na cadeia histórica da comunicação discursiva" marcada por "acúmulo" de vozes, sempre ressignificado no jogo enunciativo entre os sujeitos (Brait, 2000; Faraco, 2003; Brait; Melo, 2005). O limite do texto/enunciado está, pois, ligado à abertura para o outro e não ao fechamento numa estrutura - caso da oração, na avaliação de Bakhtin, ou de certos aspectos de textualidade, na vertente de Beaugrande e Dressler (1981).

O conceito de texto assumido neste trabalho busca, portanto, colocar em evidência aspectos da interlocução sócio-histórica na atividade verbal dos sujeitos. Trata-se, como procuro mostrar adiante, de modo de ser que se manifesta no espaço de enunciação sempre imprevisto, porque sempre por acontecer na relação com o outro, no processo de enunciação concreta, real (Voloshinov/Bakhtin, s/d: 1926). Essa ação sobre/com o outro não implica, entretanto, assunção de princípios explícitos de cooperação entre produtor e receptor do texto, na suposição de independência do indivíduo. Como explicita Lemos (1996), na avaliação da função e do destino da palavra alheia na obra de Bakhtin, trata-se de pensar o sujeito da/na linguagem como "outro do outro": "não é apenas a não-coincidência consigo próprio que está aí em jogo, mas a não-coincidência com o outro, contrária à fusão/identificação." (Lemos, 1996: 42, destaque no original). A concepção de texto - e a de sujeito que nela está implicada - interessa a este trabalho à medida que, como lembra Corrêa (2002: 66-69) em crítica à apropriação pedagógica do conceito de gêneros de discurso, muitas das "desarticulações" ou "inconsistências" observadas em atividades de escrita escolar podem ser concebidas não como "erros", mas como produto da passagem de um gênero a outro, condição da produtividade, índice da dinâmica das relações intersubjetivas e intergenéricas constitutivas da linguagem.

$\mathrm{Na}$ seção seguinte, discuto aspectos relacionados ao processo de textualização em práticas letradas acadêmicas em ambiente semipresencial. 


\section{Práticas letradas acadêmicas em contexto semipresencial}

Em trabalho anterior (Komesu, 2012), procurei discutir, com base nas concepções de letramentos acadêmicos (Lea; Street, 2009) e de aspectos "ocultos" dos letramentos acadêmicos, (Street, 2009; comentada por Corrêa, 2011), a oposição entre o que chamei de aspectos "transparentes" e aspectos "ocultos" das práticas letradas acadêmicas no contexto semipresencial da Univesp. ${ }^{5}$ Retomo, pois, de maneira breve, a concepção de letramentos acadêmicos, apresentada, pelos autores, como práticas sociais de leitura e escrita, situadas em determinado contexto, as quais abrangem do ensino fundamental ao universitário e ao pós-graduado. Segundo Lea e Street (2009: 369-370), essa concepção tem relação com a produção de sentido, identidade, poder e autoridade; coloca em primeiro plano a natureza institucional daquilo que conta como conhecimento em qualquer contexto acadêmico específico. A ideia de aspectos "ocultos" dos letramentos acadêmicos aparece, por sua vez, em Street (2009), quando da avaliação de ensaios acadêmicos redigidos por doutorandos em uma universidade norte-americana. O autor chama a atenção para o fato de aspectos cobrados na avaliação feita por supervisores, assessores e editores de revistas nem sempre ficarem evidentes no processo de ensino. Esses aspectos "ocultos" - com aspas, como lembra Corrêa (2011) - são, em particular, ligados à inscrição da voz e ao grau de envolvimento

\footnotetext{
${ }^{5}$ A propósito da questão da escrita na universidade, Fiad (2011) discute, com base em Lillis (1999), a crença de que as convenções que regulam as práticas letradas acadêmicas seriam transparentes para quem faz parte dessa comunidade. Para Lillis, citada por Fiad, as convenções são constitutivas do que a autora inglesa chama de "prática institucional do mistério": "Segundo LILLIS (1999), nessa prática, não são explicitadas ao aluno as convenções de escrita que regem especialmente os gêneros da esfera acadêmica pois o professor parte do princípio de que os estudantes já as conhecem. Na verdade, há a negação do aluno real com o qual o professor está lidando, ao não reconhecê-lo como é, há a negação da voz do aluno no processo de ensino-aprendizagem e há a negação ao estudante das convenções que regem a escrita acadêmica. Os professores esperam que os alunos saibam essas convenções que não lhes são explicitadas." (Fiad, 2011: 363). Ramires (2009: 67-69), por sua vez, com base em dados oficiais sobre produção acadêmica em duas universidades públicas brasileiras, procura discutir relações dissimétricas entre universitário e corpo docente na produção de gêneros textuais que legitimam espaços de dizer na comunidade acadêmica. Esses trabalhos buscam mostrar o "descompasso" entre conhecimento dos universitários e saberes docentes, segundo posicionamentos que se manifestam em gêneros de discurso escritos (mas não apenas), potencialmente distintos (ver, por exemplo, crítica de Corrêa, 2011).
} 
de quem escreve; à explicitação da contribuição a ser dada, considerandose a perspectiva em que o texto se apoia; ao estabelecimento oportuno dos propósitos do ensaio (Street, 2009: 11-12; Corrêa, 2011: 334).

Corrêa (2011) busca tratar desses chamados aspectos "ocultos" do letramento como índices de presumidos sociais que acompanham a realização da linguagem verbal na produção de sentido nos enunciados concretos, atuando, segundo o autor, como presumidos dos gêneros de discurso. Para Voloshinov/Bakhtin (s/d: 1926: 5), o enunciado real, constituído numa situação extraverbal do enunciado, traz à cena instância sociocultural mais ampla, o presumido, "horizonte espacial e ideacional compartilhado pelos falantes", por meio do qual emerge "unidade indissolúvel" na linguagem. Não se trata de "fenômeno puramente linguístico", nem de "força mecânica" que agiria de "fora para dentro", nem mesmo de "ato físico-subjetivo (um pensamento, uma ideia, um sentimento)" do falante da língua. "Na vida, o discurso verbal é claramente não auto-suficiente. [...] tal discurso é diretamente vinculado à vida em si e não pode ser divorciado dela sem perder sua significação." (Voloshinov/Bakhtin, s/d: 1926: 4). Na consideração dos autores russos, é de um "conjuntamente visto", "conjuntamente sabido" e de um "unanimemente avaliado" que o enunciado depende diretamente: "a situação [extraverbal] se integra ao enunciado como uma parte constitutiva essencial da estrutura de sua significação" (Voloshinov/Bakhtin, s/d: 1926: 6, grifos no original) num "fenômeno fundamentalmente social".

Para Corrêa (2011), "as formulações particulares de um texto integram dados etnográficos a serem captados [...] na história de sentido que elas carregam." O procedimento metodológico que o autor defende e o qual assumo é, pois, o de conceber dados do processo de textualização "na própria conformação discursiva nele registrada", modo de aproximar a perspectiva etnográfica à perspectiva linguístico-discursiva ou de pensar, na formulação do autor, uma perspectiva etnográfica discursiva. Trata-se, como afirma Corrêa, de "fatos de discurso simultâneos à formulação linguística, e não [de] dados que, simplesmente, refletiriam e comprovariam uma determinação prévia, seja ela ligada ao contexto situacional, social ou histórico." (Corrêa, 2011: 334-335). No que se refere à observação de práticas discursivas registradas nos textos, a perspectiva etnográfica discursiva permitiria reconhecer, por exemplo, a complexidade de relações concretas que implicam interpelações e coerções não ditas que não são, necessariamente, percebidas como tais pelos sujeitos; permitiria, assim, investigar "um descompasso quanto à relação entre o dito e o presumido [...] num dado gênero", o qual fica evidente, da parte dos alunos, na tarefa de associar gêneros conhecidos a gêneros por dominar: "não basta relacionar os gêneros do discurso com base, apenas, em suas materialidades 
linguísticas; é preciso, também, estabelecer relações entre os seus presumidos" (Corrêa, 2011: 354).

De maneira particularizada, no ambiente semipresencial da Univesp, poderse-ia dizer que o extraverbal que constitui as práticas letradas acadêmicas atua em função das atividades do universitário no que concerne a: conjuntos de habilidades tomadas como imprescindíveis para a proficiência técnica com ferramentas digitais, capacidade de gerir informação em múltiplos formatos e plataformas eletrônicas, relação (aparentemente paradoxal, porque ora a distância, ora presencial fisicamente) com tutor e colegas da turma. Mas também: reflexão crítica sobre objetos da formação acadêmica, anseio de obter diploma universitário em instituição pública de prestígio, (tentativa de) apropriação de posicionamento numa sociedade em que a formação inicial é, sempre muito rapidamente, considerada insatisfatória e obsoleta. A exemplo do que Corrêa (2012: 11) considera na reflexão sobre espaço e espacialidade na produção escrita escolar, "o presumido social que fala" no processo de textualização em ambiente semipresencial pode ser concebido como "conjunto de efeitos de um modo de ser social que ele materializa" - na tentativa de flexibilização de tempo, ${ }^{6}$ de superação das barreiras impostas pelo espaço geográfico, de democratização de acesso ao ensino superior (cf. Litto, 2012); na expectativa de valorização profissional resultante de diploma universitário, com inserção no chamado "mercado de trabalho"; na busca pela inserção numa sociedade que prestigia novas tecnologias de informação e comunicação; na permanência, enfim, do ideal de que a "alfabetização" (agora, no contexto das novas tecnologias), isto é, a apreensão de práticas de leitura e escrita, tal como prestigiada pela instituição escolar (mas não somente), é condição para mobilidade (ascensão) social, numa tendência a reconhecer valores que seriam imanentes às tecnologias (de escrita, da internet) como tais (ver, a esse respeito, críticas de Street, 1984; Graff, 1994; Marcuschi, 2001; Corrêa, 2004).

Apresento, a seguir, o conjunto do material e considerações sobre diferentes concepções de texto que emergem nas atividades digitais.

\footnotetext{
${ }^{6}$ Belloni (2009: 105) lembra que a ideia de "flexibilização" pode apresentar, pelo menos, dois sentidos contraditórios no contexto do mercado de trabalho: "de um lado, significa a possibilidade para as empresas de descartarem facilmente a mãode-obra tornada desnecessária pela introdução de novos meios tecnológicos e/ou processos de trabalho; por outro lado, porém, pode significar também processos de trabalho menos desqualificantes e menos rotineiros, propiciadores de melhores condições de trabalho." O processo de textualização pode ser ressignificado no contexto a distância e/ou semipresencial, se, por exemplo, houver desenvolvimento de atividades verbais que privilegiem o caráter de interlocução dos gêneros digitais em emergência. Esse aspecto seria, de fato, "menos rotineiro" e propiciador de outras (novas) práticas letradas não restritas ao domínio estritamente técnico dos artefafos computacionais.
} 


\section{Concepção(ões) de texto na UNIVESP}

O conjunto do material analisado é formado de 29 (vinte e nove) textos produzidos por universitários do Curso de Pedagogia semipresencial da Univesp, em 2010, em produção textual que deveria ser realizada no período virtual do curso, em aula não presencial. ${ }^{7}$ Quando do cumprimento da atividade, os universitários já haviam estudado conceitos como linguagem (denominadas "verbal" e "não verbal") e língua (como fenômeno cognitivo, cultural, social, histórico), mediante textos que integravam recursos semióticos diversos (gráfico, imagético em movimento, sonoro, digital, dentre outros). Com base na leitura de material complementar - quadro intitulado "Significado das cores", em Teoria e Prática de Diagramação, de Collaro (1996) -, o universitário deveria procurar, pelo menos, um exemplo de produto caracterizado por uma das cores apresentadas no referido quadro. Havia sugestão de embalagem de produto de alimento, de limpeza ou qualquer propaganda ou programa de televisão. O produto escolhido deveria ser "descrito em detalhes", com explicação sobre a associação entre cor e significação pretendida. Uma das recomendações da atividade era para, "se for possível, postar a imagem do produto no arquivo". Pode-se dizer que a proposta de produção textual priorizava a percepção de diferentes recursos semióticos componentes da linguagem, com destaque para utilização de instrumental gráfico, entendido como representação por figura ou desenho; reflexão sobre associação entre cor e significação; reflexão sobre transformação da língua nos dias atuais, para pensar tópicos que poderiam ser vinculados, de maneira mais direta, à discussão sobre linguagem e tecnologia na formação acadêmica.

Os textos foram selecionados segundo dois critérios: cumprimento das instruções da atividade com a postagem de uma imagem de produto no arquivo; anuência do universitário em participar da pesquisa, mediante assinatura do Termo de Consentimento Livre e Esclarecido (TCLE) do Comitê de Ética em Pesquisa (CEP) da Unesp, câmpus de São José do Rio Preto (SP). ${ }^{8}$

\footnotetext{
${ }^{7}$ Visando distinguir situações de ensino-aprendizagem em que professor (tutor, monitor) e aluno estão "exclusivamente" separados no espaço físico ou "majoritariamente" separados no espaço físico, criaram-se as expressões "educação a distância", no primeiro caso, e "educação semipresencial", no segundo, caso dos universitários inscritos na Univesp, em que o curso tem $60 \%$ de atividades on-line, promovidas por meio de tecnologias de informação (internet, TV digital), e $40 \%$ de atividades presenciais realizadas em dois encontros semanais com tutores.

${ }^{8}$ Parecer CEP/Unesp/São José do Rio Preto n ${ }^{0}$. 059/10. Informações como nome do universitário, nome do tutor, localidade geográfica do polo foram excluídas para preservar a identidade física dos participantes.
} 
Diferentemente do que apresentei em trabalho anterior (ver Komesu, 2012), proponho, neste artigo, discutir concepção(ões) de texto que emerge(m) da multiplicidade de perspectivas em ambiente semipresencial.

Considerando-se a colocação da imagem do produto na composição do texto na tela do computador, as análises mostraram igual predominância da disposição na posição central (8 textos no conjunto total, ou 27,6\%), a exemplo da Figura 1, e na posição superior à esquerda ( 8 textos, 27,6\%), como na Figura 2:

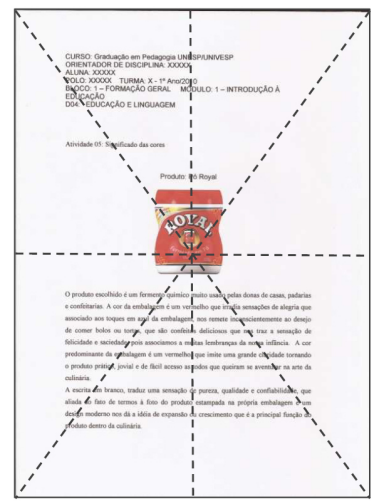

Fig. 1: $01 . \mathrm{A} .05^{9}$

${ }^{9} \mathrm{~A}$ codificação dos elementos separados por ponto se refere a: identificação do escrevente representada por número aleatoriamente atribuído ao nome; tipo de proposta de produção textual no conjunto do material e número da proposta segundo classificação no Caderno de Formação (2010). As linhas tracejadas transversais (esquerda para direita, direita para esquerda), vertical e horizontal foram acréscimos por mim feitos com o objetivo de colocar em destaque a colocação da imagem do produto na composição do texto. 


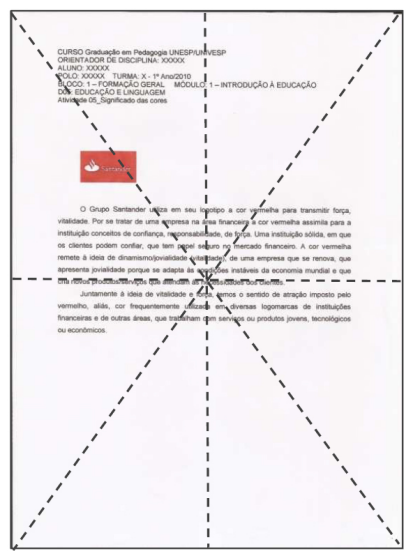

Fig. 2: 29.A.05

A disposição da imagem do produto também foi encontrada na posição central superior (7 textos, 24,1\%), como aparece na Figura 3:

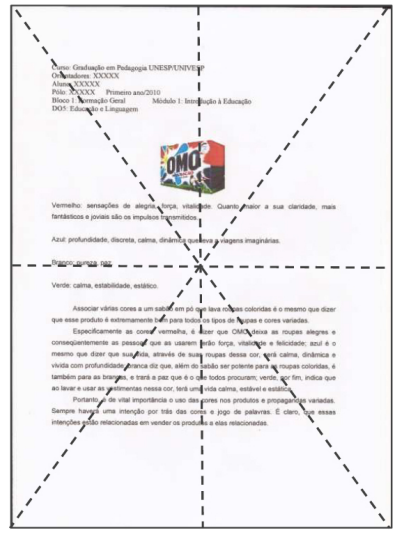

Fig. 3: 12.A.05

Em menor proporção, houve distribuição da imagem do produto na posição inferior à esquerda (4 textos, 13,8\%), como na Figura 4: 


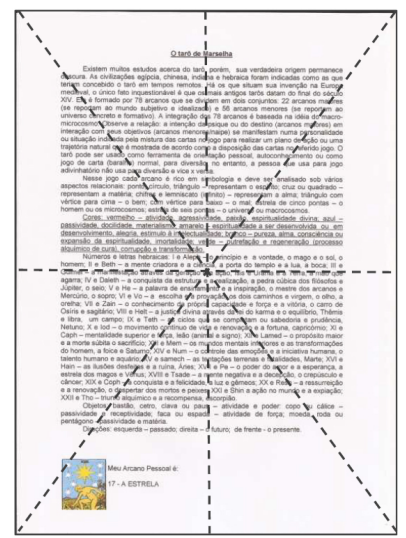

Fig. 4: 21.A.05

Por fim, foram encontrados 02 textos, o equivalente a $6,9 \%$ do conjunto do material, em que a disposição da imagem do produto foi feita na posição central inferior, como na Figura 5:

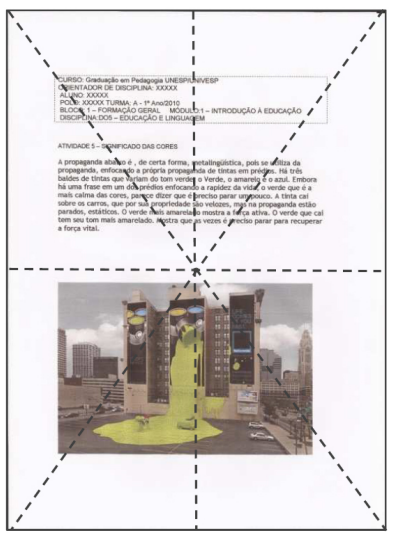

Fig. 5: 44.A.05

É sabido que a leitura, como prática social, demanda certa trajetória do olhar condicionada por hábitos, costumes, convenções, gestos, experiências dos diversos grupos na apropriação do objeto cultural (ver Chartier, 1998: 77). Numa tradição dita ocidental, é possível dizer que a recepção do texto no processo de leitura é culturalmente direcionada de um ponto em posição superior à esquerda para posição inferior à direita, num movimento de cima 
para baixo. Esse eixo de orientação é privilegiado em práticas ocidentais de leitura como um dos mais eficazes no reconhecimento de informação numa "massa homogênea" que compõe a mancha gráfico-visual do texto. A posição central desperta interesse segundo, o que é compreensível, se se pensar que se trata da região de encontro das diagonais no espaço de uma página. A posição superior à direita e a posição inferior à esquerda viriam depois numa escala de interesse no processo de leitura. Este é o chamado "Princípio do Diagrama de Gutemberg", em estudos de programação visual:

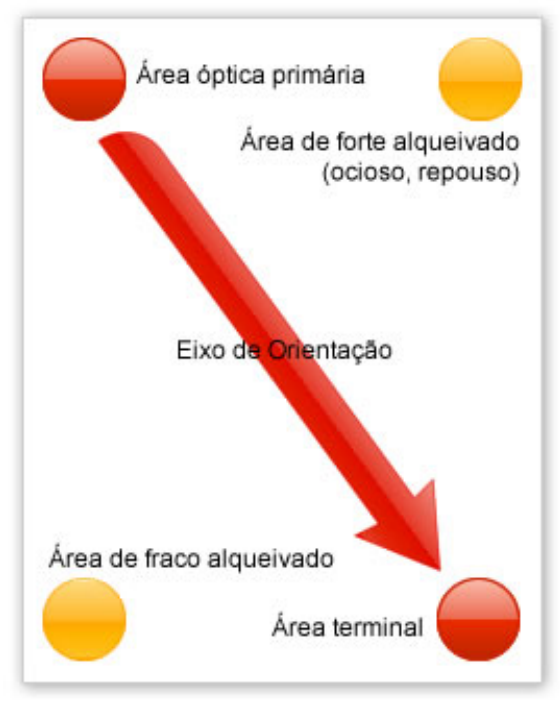

Fig. 6: Diagrama de Gutemberg - Disponível em: http://www.revistaleaf.com.br/diagrama-de-gutenberg/1144/. Acesso em: 19 abr.2012.

Não parece ser imotivado o fato de $86 \%$ das atividades realizadas terem apresentado a imagem do produto em posição superior à esquerda da página ou na posição central, com deslocamento pouco acima ou pouco abaixo desse plano de maior atração visual. Mas se, de um ponto de vista mais cognitivo, a orientação privilegiada da leitura é reconhecida, ainda que inconscientemente, pelo universitário, de outro, mais historicizado, situado no contexto de produção acadêmica semipresencial, resta problematizar o fato de a instituição projetar, na ideia de aluno autônomo, concepção de texto caracterizada pelo suposto conhecimento discente do uso de suporte e da produção de efeitos de sentido na linguagem. Destaco também o fato de não ter encontrado 
imagem na posição inferior à direita, espaço privilegiado no olhar ocidental. Em contrapartida, foram encontrados 04 textos, correspondentes a quase $14 \%$ do conjunto analisado, em posição inferior à esquerda, área de menos relevância no reconhecimento de informação visual. O modo de organização do texto parece assim prescindir de reflexão teórica na atividade de relacionar diferentes recursos semióticos. ${ }^{10}$ Em Komesu (2012), sinalizei que, de uma perspectiva discursiva, essa aparente ausência de sistematização aponta para o diálogo sócio-histórico que o universitário estabelece com outros textos já falados/ouvidos e escritos/lidos, numa tentativa de formulação de um "novo". Práticas como as que envolvem leitura de periódicos impressos e eletrônicos (jornal e revista, por exemplo), de livros e manuais didáticos, poderiam servir de referência para reconhecimento e reprodução (ressignificação) de certa disposição gráfica.

Da perspectiva do universitário em contexto semipresencial, a concepção de texto que emerge pode ser caracterizada como réplica ao comando de atividade escolar: escolha um produto; discuta relação entre cor e significação pretendida; se possivel, insira imagem do produto no cumprimento de (mais uma) tarefa. É na "flutuação" de tratamento da qualidade da imagem em pixels (pontos luminosos que formam a imagem na tela do computador), ora excelente, ora fraca; na falta de sistematização em indicar referência bibliográfica de onde foram extraídas as imagens; na ausência de cuidado na articulação entre o que é "verbal" e "visual" e, sobretudo, na ausência de investimento no caráter interlocutivo previsto na atividade que aparece concepção tradicional de texto, reconhecida, principalmente, como texto de base gráfica, produzido na escola, embora a proposta priorizasse relação entre diferentes recursos semióticos, em contexto de produção que, por hipótese, permitiria acesso "ilimitado" a todo e qualquer (hiper)texto, com possibilidade de circulação sem precedentes. O "presumido social que fala" nas atividades verbais em surgimento demanda, pois, da formação acadêmica do universitário, práticas de leitura e escrita que lhe permitam gerir informação em múltiplos formatos e plataformas eletrônicas, na projeção de lugar reconhecido socialmente (pelo outro, no outro); demanda também reflexão crítica sobre objetos da formação acadêmica, na constituição dos enunciados genéricos.

\footnotetext{
${ }^{10}$ Contrariamente, parece não haver conflito na distribuição espacial do elemento "gráfico" do texto escrito (supondo que o digital seja impresso), organizado de cima para baixo, da esquerda para a direita, na ordem canônica de leitura e escrita em práticas ocidentais, com emprego de parágrafo e de letras maiúsculas e minúsculas, sobretudo, em cor preta.
} 
Da perspectiva da instituição, prevalecem, na concepção de texto, aspectos estruturais (entendidos como coerência, coesão, correção gramatical, diagramação) e aspectos pragmáticos (entendidos como cumprimento de prazos e participação - saber - das pessoas, no sentido de ritual), sem destaque para aspectos discursivos, embora esses possam ser reconhecidos em parte do referencial teórico sobre língua e linguagem recomendado pela instituição (Sangalli, 2012). Aspectos estruturais e procedimentais seriam, pois, da ordem da "transparência"- com aspas, supondo que esta seja algo possível na ordem dos discursos - da universidade. Falta, como destacado (Komesu, 2012), orientação prévia no quadro institucional para:

i. composição de textos multissemióticos, considerando-se escolha de cores; contraste entre figura e fundo; tratamento da imagem; utilização de software;

ii. inserção de hiperlink, ${ }^{11}$ considerando-se modo de circulação dos textos em ambiente digital;

iii. pesquisa em bancos de dados de imagem na rede ou fora dela;

iv. recurso ao texto alheio, para a projeção de auto-imagem como autor de texto acadêmico;

v. reflexão sobre recepção e produção de textos no contexto das múltiplas semioses.

\footnotetext{
${ }^{11}$ Universitário e tutor (mas não somente) teriam a ganhar se refletissem a respeito de definição linguístico-discursiva - portanto, distante de questão meramente técnica - de hiperlink. Acredito que o hiperlink pode ser concebido tanto da perspectiva da recepção quanto da produção como ponto de heterogeneidade mostrada (Authier-Revuz, 2004), modo de negociação que produz como efeito "aproximação" do sujeito ao interdiscurso, supondo-se que a linguagem pudesse ser localizada, por exemplo, no suporte. Penso que esses pontos de heterogeneidade mostrada, comumente identificados nesses elementos de hipermídia formados por recurso gráfico (mas também por recurso imagético estático ou em movimento, por recurso sonoro, dentre outros), podem também ser confrontados com práticas letradas outras, consideradas tradicionais, como entrada em dicionários e nota de rodapé na estrutura de textos manuscritos e impressos, modo produtivo de observar o caráter sócio-histórico das relações intergenéricas constitutivas de gêneros em emergência.
} 
A exemplo do que diz Zavala (2010) no contexto peruano, com a expansão do ensino superior se assume que os universitários chegam à instituição prontos para responder às demandas de práticas letradas que esse nível lhes exige. Assim, pressupõe-se, em ambiente semipresencial, que o universitário não apenas tem ou terá conhecimentos letrados sobre gêneros de discurso diversos, mas sabe ou saberá, igualmente, lidar com formas de suporte diversas (caderno, livro, apostila, mídia de CD-ROM e de DVD, tela do computador), instrumentos empregados na atividade de escrita (lápis, papel, caneta, teclado do computador, mouse, mousepad), forma da escrita (maiúsculas, minúsculas; organização tipográfica; design da letra, cor), organização dos signos no campo gráfico (composição da página, com inserção de hiperlinks para outras páginas eletrônicas e de arquivos de áudio e vídeo) na constituição do texto eletrônico propriamente dito (ver Fraenkel, 2004; Kress e Van Leeuwen, 2001; 2006; Scollon e Scollon, 2009). Parece que se supõe, assim, que o texto (a linguagem) pode ser localizado(a) e instrumentalizado(a) no suporte. Os estudos etnográficos discursivos podem contribuir com a reflexão sobre concepção(ões) de texto e textualização nas atividades em emergência. Não se trata de pensar "aprimoramento" da relação ensino-aprendizagem ou "eficácia" do processo de comunicação ou formação, mas (novos) modos de discutir, atuar, valorizar, colocar em confronto - enunciar (em) - práticas de leitura e escrita contemporâneas.

\section{Considerações finais}

Neste artigo, procurei discutir concepções de texto que emergem das relações entre universitário e instituição no processo de textualização em contexto semipresencial. Busquei mostrar que o aparecimento do texto não se restringe a - não pode ser pensado como - aspectos estruturais, procedimentais ou técnicos que podem (devem) ser manipulados segundo competências individuais do aluno. A passagem de certa noção de texto para a noção de enunciado genérico objetivou colocar em evidência relação radicalmente dialógica entre o que é tomado como verbo-visual e o que é concebido como situação extraverbal na linguagem. Como propõe Corrêa (2002, 2011) na aproximação entre a perspectiva etnográfica e a perspectiva linguísticodiscursiva nos estudos de escrita, é por meio desse exame de práticas letradas institucionalizadas que o pesquisador pode priorizar o acontecimento discursivo de que o processo de textualização é feito, sem se fixar em "modelos", os quais, repetidos pelos discentes e cobrados à exaustão por professores/tutores nas instituições, correspondem "à negação da mobilidade das relações intergenéricas 
constitutivas dos gêneros de discurso" (Corrêa, 2002: 69), portanto, à recusa do caráter histórico da linguagem.

No caso dos textos analisados, no que se refere a recursos semióticos mobilizados e atualizados na produção do universitário que utiliza computador com acesso à internet no processo de textualização a distância/semipresencial, a aparente ausência de sistematização na colocação da imagem, aquilo que poderia ser concebido como "erro" ou "equívoco", falta de conhecimento/saber do universitário, falta de orientação/instrução da instituição, pode, por um lado, ser projetado numa dimensão "oculta" das práticas letradas acadêmicas. Dessa perspectiva, detectar "fissuras" por onde o texto "escapa", enumerá-las e propor soluções para a produção textual multissemiótica seriam modos de conceber texto, mais próximo a práticas valorizadas por instituições como a escola ou a universidade. Por outro lado, a exemplo do que diz Corrêa (2002, 2004, 2011), o processo de textualização da fala/escrita se particulariza no sujeito e aquilo que é sempre imprevisto nos textos, porque está sempre por acontecer na relação com outro - por exemplo, escolha e disposição de figura na composição da página na tela do computador, mas também o que é dito e como o escrito é disposto como réplica à atividade acadêmica - pode ser pensado como "respostas que denunciam a convivência de práticas sociais, as quais, por sua natureza histórica, se transformam, estabelecendo novas relações dialógicas" com os enunciados alheios (Corrêa, 2002: 69).

Com base no percurso teórico-metodológico traçado, gostaria de encerrar esta reflexão apontando para uma concepção de texto para os estudos de enunciação digital que privilegiam a integração entre múltiplas semioses. Para tanto, recorro aos trabalhos de McKenzie (1999) e Melià (2010). Do ponto de vista da teoria crítica, McKenzie (1999) observa que os processos históricos por meio dos quais os textos foram reconhecidos, ao longo dos séculos, já se aceleraram de tal modo que não é mais possível "definir e localizar a autoridade do texto ao estilo antigo", na condição material de livro. Segundo o autor, "bibliotecários profissionais, sob a irresistível pressão das mudanças tecnológicas e sociais, redefinem sua disciplina, com a finalidade de descrever, alojar e ter acesso a som, imagem estática e em movimento, com ou sem palavras, e ao fluxo de informações armazenadas em computador." (McKenzie, 1999: 1). McKenzie propõe, pois, refletir sobre a existência de diferentes estruturas de texto na condição de "livros", mas também de "não livros" reconhecidos em mapas, filmes, bancos de dados e também na tradição oral. Fica evidente, na reflexão desse autor, a preocupação em discutir a noção de suporte como condição do texto; para o que me interessa, a discussão proposta por McKenzie permite ainda pensar uma concepção de texto que não seja exclusivamente fundada em recurso semiótico gráfico. 
De uma perspectiva eurocêntrica, diz o autor, texto é sempre concebido segundo o primado da escrita. Citando Spencer e Gillen (1927), ${ }^{12}$ McKenzie (1999: 40) observa, em práticas de aborígenes australianos, os Arunta, que cada aspecto proeminente da geografia do país é associado a algum grupo totêmico, numa topografia totêmica. Não se trata apenas, diz McKenzie, da sacralização dos objetos, embora possa assim ser considerado, mas de uma sua função textual (narrativa) na linguagem humana. Ao se referir a um mapa, McKenzie lembra que a relação desse objeto com a realidade é "como a de palavras para o mundo - quase totalmente arbitrária, não mimética", uma vez que envolve escalas e omissão de detalhes na projeção gráfica (McKenzie, 1999: 43).

Ainda procurando argumentar favoravelmente a estruturas diversas de textos na condição de "não livros", McKenzie retoma a história da colonização britânica na Nova Zelândia, mais especificamente, no episódio do Tratado de Waitangi, firmado em 1840, por meio do qual, na versão inglesa, chefes maoris teriam cedido a soberania de suas terras para a coroa britânica. O tratado, assinado em maori e inglês, tornou-se conhecido porque há aspectos divergentes nas versões, o que promoveu e tem promovido, até a atualidade, conflitos entre descendentes de maoris e de britânicos, no que diz respeito à posse e legitimidade de terras e riquezas. Mas não somente: o autor ressalta que, para os autóctones, a relação com a terra é menos de valor comercial e mais de status simbólico, índice de pertença a certo grupo social considerado de prestígio. McKenzie discute o fato de que a assinatura do documento foi precedida por curto período de tempo - aproximadamente 20 anos -, correspondente à chegada dos europeus às ilhas e à meteórica passagem de uma cultura oral para uma cultura letrada, com introdução da imprensa moderna no cotidiano dos habitantes nativos. Tratar-se-ia, na avaliação do autor, do equivalente à revolução de Gutenberg na Europa do século XV, mas de modo muito mais abreviado. $\mathrm{O}$ autor destaca ainda que, 25 anos antes da assinatura do tratado, os aborígines poderiam ser considerados "completamente analfabetos" numa cultura oral caracterizada por um corpo próprio de mitos (McKenzie, 1999: 81); as missões católica e protestante foram, nesse aspecto, fundamentais para a alfabetização e catequização dos indígenas e para a posterior inserção de "assinatura" dos chefes maoris no tratado.

Entretanto, "a destreza para assinatura do próprio nome foi uma armadilha", não porque o tratado tenha sido uma fraude ou o documento não tivesse utilidade, mas porque o texto escrito é testemunha apenas parcial de um acontecimento que não se resumiu (não pode ser resumido) à palavra escrita (McKenzie, 1999: 117-120). Algumas podem ser consideradas assinaturas no sentido usual, mas a maior parte delas, diz McKenzie, apresentavam "disposições espaciais complicadas" que sugeririam representações de recursos naturais (vales, rochedos, colinas, montanhas) das terras tribais das quais o signatário provinha (McKenzie, 1999: 42), como pode ser visto na Figura 7:

${ }^{12}$ SPENCER, B.; GILlen, F. J. 1927. The Arunta... a Stone Age People. 2. v. London: Macmillan apud McKENZIE, D. F. 1999. 


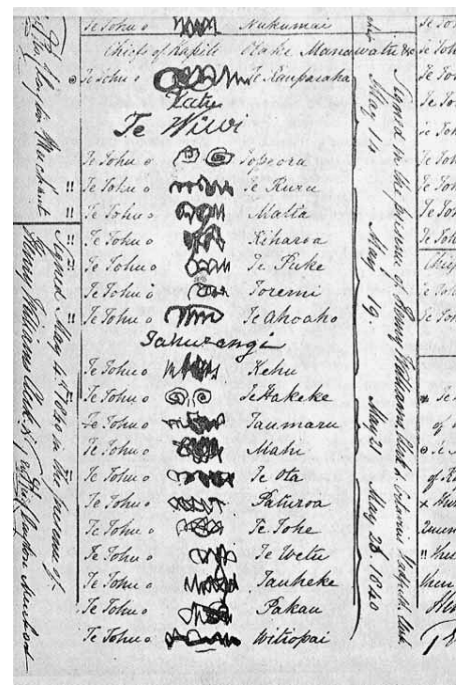

Fig. 7: Folha suplementar do Tratado de Waitangi com assinatura de chefes maoris (McKenzie, 1999: 119)

O que constitui um texto, na visão de McKenzie, "não é a presença de elementos linguísticos, mas o ato de construção" simbólica e, desse ponto de vista, o texto pode ser concebido como paisagem, "sinal da terra [que] faz um homem" (McKenzie, 1999: 43). Se, como afirma o autor, a aceleração dos processos históricos tem dificultado a possibilidade de definição e localização da "autoridade do texto ao estilo antigo", os (novos) contornos de que o texto é feito podem ser delineados no modo como os sujeitos ocupam o espaço na enunciação (do texto). A esse respeito, retomo os estudos de Melià (2010), pesquisador da cultura guarani que, em entrevista concedida a um portal brasileiro, ao ser indagado sobre a realidade etnográfica e o processo histórico daquele povo, explicou que os guarani escolheram climas úmidos, de temperatura média, à margem de rios e lagunas para a produção agrícola. "Mas a ecologia guarani não é só natureza, nem se define pelo seu valor exclusivamente produtivo", explica Melià. De acordo com o autor:

Com uma expressão que lhe é muito característica, o guarani se refere ao seu território como "tekoha". Pois bem, se o "teko" é o modo de ser, o sistema, a cultura, a lei e os costumes, o "tekoha" é o lugar e o meio em que se dão as condições de possibilidade do modo de ser guarani. Com os próprios dirigentes guarani, é preciso dizer que sem "tekoha" não há "teko". (MELIÀ, 2010) 
Acredito, pois, que a relação entre lugar/meio e modo de ser, dito de outro modo, a relação com o espaço na constituição das possibilidades dos modos de ser dos guarani, na explicação de Melià, na condição de "sinal da terra [que] faz um homem", na avaliação de McKenzie (1999), é maneira produtiva de refletir sobre uma noção de texto no processo de textualização a distância/semipresencial. É sabido que a relação com o espaço é sempre cultural. Do ponto de vista da recepção, por exemplo, a apropriação do texto no momento da leitura, segundo determinado percurso, é índice dessa relação historicizada, como procurei discutir na análise dos dados. Do ponto de vista antropológico, o vínculo entre lugar e cultura, leis, costumes, é condição de possibilidade da subjetividade. A complexa relação entre espaço e cultura é tão notória que Melià enfatiza, com os dirigentes guarani, que sem lugar (sem espaço) não há modo de ser.

Refletindo, de maneira geral, sobre práticas de produção de textos acadêmicos no contexto digital e, de maneira particularizada, sobre o conjunto do material na Univesp, o espaço semipresencial de constituição dos textos parece impor ao universitário relação ambígua: trata-se, ao mesmo tempo, de espaço de ocupação presencial $e$ não presencial. É certo que, de um ponto de vista dialógico, ao menos em um sentido, as relações são sempre presenciais, uma vez que demandam do universitário a representação do outro na atividade verbal, ainda que as aulas imponham "jogo" entre distanciamento espacial e aproximação temporal (síncrona/assíncrona) na relação entre professor e aluno. A exemplo do que diz Melià (2010) sobre a busca dos guarani de uma "terra sem males" - experiência indígena de pensar o projeto (utópico) de uma sociedade mais solidária e humana, a qual seria, ao mesmo tempo, geográfica e espiritualmente localizável - o universitário em contexto semipresencial tem de buscar constituir-se como escrevente num espaço que o atravessa como sujeito da contemporaneidade. A relação ambígua com o espaço na constituição de um modo de ser parece igualmente complexa do ponto de vista da instituição, se se considerar que a proposta do curso, com $60 \%$ das atividades não presenciais, sugere que uma das modalidades de avaliação seja a prova presencial escrita ao final de cada disciplina. Considerando-se o estatuto da avaliação como instrumento de verificação que objetiva determinar a competência de um profissional que visa a um diploma, a obrigatoriedade da prova presencial é crucial, uma vez que é um dos instrumentos que permite dizer se o universitário está ou não aprovado no curso e apto a exercer a profissão. O espaço na Univesp define-se, desse modo, presencialmente, no processo de ensino/aprendizagem semipresencial.

No processo de textualização, há o trabalho do sujeito que historiciza a linguagem na emergência de enunciados concretos, porque reais, marcados pela história de suas ocorrências e pelo "acúmulo de vozes" que caracterizam 
todo e qualquer enunciado. O recurso a diferentes semioses, não somente de base gráfica, mas também sonora, visual estática, visual em movimento etc., na composição (ocupação, constituição do espaço) do texto em contexto acadêmico semipresencial tem de lidar com a emergência desses enunciados concretos. Nessa situação enunciativa, o sujeito escrevente (se) constitui (n)um novo "espaço de escrita". O cumprimento da tarefa acadêmica, no entanto, pode ser marcado por imprevistos, como distribuição espacial "inesperada" da figura (mas não somente), porque não obedeceria a critérios culturalmente estabelecidos ou, ainda, não discutidos em práticas letradas acadêmicas. Nenhum desses fatores elimina, porém, o trabalho do sujeito de marcar(-se), no (seu) texto, relação sócio-histórica com outros textos e múltiplas semioses, des-centralizadas, dispersas, não-lineares, abertas a um exercício da ordem do coletivo, como atribuído, por autores como Lankshear e Knobel (2011: 51-55), ao paradigma de uma sociedade pós-moderna. Esse diálogo incessante com práticas sociais outras, num diálogo incessante com enunciados alheios, parece colocar em evidência, no processo de textualização de acadêmicos, relação entre lugar/meio e modo de ser, ocupar o espaço na enunciação (do texto) na contemporaneidade, na apropriação e mobilização de recursos semióticos que não sejam restritos nem apenas reconhecidos a/como os de ordem gráfica. Talvez este seja ponto relevante a ser incluído numa agenda de estudos linguísticos da atualidade.

\section{Referências}

ABDALLA, Maria de Fátima B. 2010. Linguagem, Educação e Formação de Professores. Caderno de formação 2. São Paulo: Cultura Acadêmica. 118.

ARAÚJO, Júlio César. 2007. Os gêneros digitais e os desafios de alfabetizar letrando. Trabalhos em Lingüistica Aplicada 46. 79-92.

ARAÚJO, Júlio César; DIEB, Messias. 2009. (Org.) Letramentos na web: gêneros, interação e ensino. Fortaleza: Edições UFC.

AUTHIER-REVUZ, Jacqueline. 2004. Entre a transparência e a opacidade: um estudo enunciativo do sentido. Tradução: Marlene Teixeira. Porto Alegre: Edipucrs. 11-79.

BAKHTIN, Mikhail. 1997. O problema do texto. In: . Estética da criação verbal. 2. ed. Tradução feita a partir do francês: Maria Ermantina Galvão G. Pereira. São Paulo: Martins Fontes. 327-358.

BENTES, Anna Christina. 2008. Lingüística Textual. In: MUSSALIM, Fernanda; BENTES, Anna Christina. (Org.) Introdução à linguística: domínios e fronteiras. 8.ed. v.1. São Paulo: Cortez. 245-285. 
BRAIT, Beth. 2000. PCNs, gêneros e ensino de língua: faces discursivas da textualidade. In: ROJO, Roxane. (Org.) A prática de linguagem em sala de aula: praticando os PCNs. Campinas (SP): Mercado de Letras. 15-25.

BRAIT, Beth; MELO, Rosineide de. 2005. Enunciado/ enunciado concreto/ enunciação. In: BRAIT, Beth. (Org). Bakhtin: conceitos-chave. 2. ed. São Paulo: Contexto. 61-78.

BEAUGRANDE, Robert-Alain de; DRESSLER, Wolfgang U. 1981. Introduction to text linguistics. London; New York: Longman. 1-13.

BELLONI, Maria Luiza. 2009. Educação a distância. 5.ed. Campinas: Autores Associados.

BUZATO, Marcelo El Khouri. 2007a. Desafios empírico-metodológicos para a pesquisa em letramentos digitais. Trabalhos em Lingüistica Aplicada 46. $45-62$.

BUZATO, Marcelo El Khouri. 2007b. Entre a Fronteira e a Periferia: linguagem e letramento na inclusão digital. 2007. 285 f. Tese (Doutorado em Linguística Aplicada) - Instituto de Estudos da Linguagem, Universidade Estadual de Campinas.

BUZATO, Marcelo El Khouri. 2006. Letramentos Digitais e Formação de Professores. Anais do III Congresso Ibero-Americano Educarede. São Paulo: CENPEC. 81-86.

BRAGA, Denise Bértoli. 2007. Letramento na internet: o que mudou e como tais mudanças podem afetar a linguagem, o ensino e o acesso social. In: KLEIMAN, Angela B.; CAVALCANTI, Marilda C. (Org.) Lingüistica Aplicada: suas faces e interfaces. Campinas: Mercado de Letras. 181-198.

BRASIL. 1996. Lei 9.394, de 20 de dezembro de 1996. Estabelece as diretrizes e bases da educação nacional. Brasília. Disponível em: $<$ http://www.planalto.gov.br/CCIVIL /leis/L9394. Acesso em: 20 nov.2009.

CADERNO DE FORMAÇÃO: introdução à Educação. 2010. São Paulo: Cultura Acadêmica.

COLlARO, Antonio Celso. 1996. Teoria e prática de diagramação. São Paulo: Summus.

COLLINS, Heloisa. 2008. Distance Learning, Autonomy Development and Language: discussing possible connections. DELTA: Documentação de Estudos em Lingüística Teórica e Aplicada 24. 529-550.

COLLINS, Heloisa; FERREIRA, Anise. 2004. (Org.) Relatos de experiência de ensino e aprendizagem de línguas na internet. Campinas: Mercado de Letras. 
COSTA, Ana Paula Martinho da; TAVARES, Kátia Cristina do Amaral. 2008. A Internet no ensino presencial de línguas: implicações para a formação do professor. In: ZYNGIER, Sonia; VIANA, Vander; SILVEIRA, Natália. (Ed.) Ver 83 visualizar: letras sob o prisma empírico. Rio de Janeiro: Publit e Faculdade de Letras da UFRJ. 125-142.

COSTA VAL, Maria da Graça. 2004. Redação e textualidade. São Paulo: Martins Fontes.

CORRÊA, Manoel Luiz Gonçalves. 2011. As perspectivas etnográfica e discursiva no ensino da escrita: o exemplo de textos de pré-universitários. Revista da ABRALIN, v. Eletrônico, n. Especial, 2a . parte. 333-356.

CORRÊA, Manoel Luiz Gonçalves. 2012. Espaço e espacialidade na produção escrita escolar: a reflexão linguístico-discursiva no ensino da escrita. Scripta (PUCMG), v. 16. 91-113.

CORRÊA, Manoel Luiz Gonçalves. 2001. Letramento e heterogeneidade da escrita no ensino de Português. In: SIGNORINI, Inês. (Org.). Investigando a relação oral/escrito e as teorias do letramento. Campinas: Mercado de Letras. 135-166.

CORRÊA, Manoel Luiz Gonçalves. 2002. Linguagem $\&$ comunicação social: visões da lingüística moderna. São Paulo: Parábola Editorial.

CORRÊA, Manoel Luiz Gonçalves. 2004. O modo heterogêneo de constituição da escrita. São Paulo: Martins Fontes.

FARACO, Carlos Alberto. 2003. Linguagem $\&$ diálogo: as idéias lingüísticas do círculo de Bakthin. Curitiba (PR): Criar Edições.

FIAD, Raquel Salek. 2011. A escrita na universidade. Revista da ABRALIN, v. Eletrônico, n. Especial, 2a ${ }^{\mathrm{a}}$ parte. 357-369.

FIORIN, José Luiz. 2006. Introdução ao pensamento de Bakhtin. São Paulo: Ática.

FREIRE, Maximina Maria. 2009. Formação tecnológica de professores: problematizando, refletindo, buscando. In: SOTO, Ucy; MAYRINK, Mônica Ferreira; GREGOLIN, Isadora Valencise (Org.) Linguagem, educação e virtualidade: experiências e reflexões. São Paulo: Cultura Acadêmica. 13-28.

GEE, James Paul; HAYES, Elizabeth R. 2011. Language and Learning in the Digital Age. London and New York: Routledge.

KOCH, Ingedore Grunfeld Villaça. 2009. Introdução à linguística textual: trajetórias e grandes temas. 2.ed. São Paulo: Martins Fontes.

KOMESU, Fabiana. 2012. Letramentos acadêmicos e multimodalidade em contexto de EaD semipresencial. Scripta (PUCMG), v. 16. 75-90. 
LANDOW, George P. 2002. Educational innovation and hypertext: one university's successes and failures in supporting new technology. In: SNYDER, Ilana. Silicon Literacies: Communication, innovation and education in the electronic age. London and New York: Routledge. 101-129.

LANKSHEAR, Colin; KNOBEL, Michele. 2011. New literacies. 3.ed. England: Open University Press.

LEA, Mary R.; STREET, Brian V. 2006. The "Academic literacies" model: theory and applications. Theory Into Practice 45, n. 4. 368-377.

LILLIS, Theresa. 1999. Whose "Common Sense"? Essayist literacy and the institutional practice of mystery. JONES, Carys; TURNER, Joan; STREET, Brian. (Org.) Students writing in the university: cultural and epistemological issues. Amsterdam: John Benjamins. 127-140.

LITTO, Fredric. 2012. Quais são os pontos positivos da Educação a distância? Disponível em: http://www2.abed.org.br/faq.asp?Faq_ID=18. Acesso em: 17 abr. 2012.

MACHADO, Irene. 2005. Gêneros discursivos. In: BRAIT, B. (Org.) Bakhtin: conceitos-chave. 2.ed. São Paulo: Contexto. 151-166.

MAIA, Ivan Ferrer et al . Desenvolvimento da relação de cooperação mediada por computador em ambiente de educação a distância. Interface (Botucatu), Botucatu , v. 10, n. 20, dez. 2006 . Disponível em <http://www.scielo.br/scielo.php?script $=\mathrm{sci}_{a}$ rttext\&pid $=$ S1414$32832006000200011 \& \operatorname{lng}=\mathrm{pt \& nrm}=\mathrm{iso}>. \quad$ acessos em 13 fev. 2013. http://dx.doi.org/10.1590/S1414-32832006000200011.

MARCUSCHI, Luiz Antônio. 1983. Lingüística de texto: o que é e como se faz. Recife: Universidade Federal de Pernambuco. Debates 1.

MANUAL ACADÊMICO. 2010. São Paulo: Cultura Acadêmica.

MANUAL DO ALUNO. 2010. São Paulo: Cultura Acadêmica.

MANUAL OPERACIONAL DO AVA UNESP. 2010. São Paulo: Cultura Acadêmica.

McKENNA, Michael C.; PROCTOR, Kenneth M. 2006. The Role of Technology in the Professional Development of Literacy Educators. In: McKENNA, Michael C.; LABBO, Linda D.; KIEFFER, Ronald D.; REINKING, D. (Ed.) International Handbook of Literacy and Technology II. Mahwah, New Jersey: Lawrence Erlbaum Associates. 273-286.

McKENZIE, Donald F. 1999. Bibliography and the Sociology of Texts. Port Chester (NY): Cambridge University Press. 
MELIÀ, Bartomeu. 2010. "A história de um guarani é a história de suas palavras": entrevista a Patricia Fachin. Tradução: Moisés Sbardelotto. Disponível em: http://www.ihuonline.unisinos.br/index.php?option=com_content $\&$ view $=$ article\&id $=3258 \&$ secao $=331$. Acesso em: 09 mar.2012.

MOORE, Michael; KEARSLEY, Greg. 2007. Educação a distância: uma visão integrada. Tradução: Roberto Galman. São Paulo: Thomson Learning.

PAHL, Kate; ROWSELL, Jennifer. 2005. Literacy and Education: Understanding the New Literacy Studies in the Classroom. London: Paul Chapman Publishing.

RAMIRES, Vicentina. 2007. Gêneros textuais e relações de poder na comunidade acadêmica. Veredas On Line - Atemática 01/2007. 66-79.

SANGALLI, Michele. 2011. Língua(gem) na rede: a visão dos universitários no contexto de educação a distância semipresencial. Projeto de Pesquisa (Iniciação Científica) financiado pela Fundação de Amparo à Pesquisa do Estado de São Paulo (processo 2011/23111-7).

SARMET, Maurício Miranda; ABRAHAO, Júlia Issy. O tutor em Educação a Distância: análise ergonômica das interfaces mediadoras. Educ. rev., Belo Horizonte , n. 46, dez. 2007 . Disponível em <http://www.scielo.br/scielo.php?script $=$ sci $_{a}$ rttext\&pid=S0102$46982007000200004 \& \operatorname{lng}=$ pt\&nrm $=$ iso $>$. acessos em 13 fev. 2014. http://dx.doi.org/10.1590/S0102-46982007000200004.

STREET, Brian V. 2009. "Hidden" features of academic paper writing. Working Papers in Educational Linguistics 24. 1-17.

UNIVESP. Geraldo Alckmin assina projeto de lei para a criação da Fundação Univesp. Disponível em: http://www.univesp.ensinosuperior.sp.gov.br /3254/geraldo-alckmin-assina-projeto-de-lei-para-a-criacao-da-fundacaounivesp. Acesso em: 18 abr.2012.

VOGT, Carlos; LOYOLLA, Waldomiro; ARCHANGELO, Jocimar; DI GIOVANNI, Geraldo. 2009. UNIVESP. São Paulo: Imprensa Oficial do Estado de São Paulo.

VOLOSHINOV, Valentin Nikolaevich; BAKHTIN, Mikhail Mikhailovich. Discurso na vida e discurso na arte (sobre poética sociológica). 1926. Tradução para uso didático da versão inglesa de 1976: Carlos Alberto Faraco e Cristóvão Tezza, s/d. (Texto originalmente publicado em russo, em 1926).

XAVIER, Antônio Carlos dos Santos. 2005. Letramento digital e ensino. In: SANTOS, Carmi Ferraz; MENDONÇA, Márcia. (Org.) Alfabetização e letramento: conceitos e relações. Belo Horizonte: Autêntica. 133-148.

ZAVALA, Virgínia. 2010. Quem está dizendo isso?: letramento acadêmico, identidade e poder na educação superior. In: VÓVIO, Claudia Lemos; 
Concepção(ões) de texto em contexto de EaD...

Text conception(s) in context of semi-present...

333

SITO, Luanda; GRANDE, Paula Baracat de. (Org.) Letramentos: rupturas, deslocamentos e repercussões de pesquisas em linguística aplicada. Campinas: Mercado de Letras. 71-95.

Recebido em: 10/09/2012

Aceito em: 09/10/2012 